Génét. Sél. Evol., 1986, 18 (2), 131-144

\title{
Endemic microorganisms of a Drosophila simulans strain and their relationships with the non-mendelian transmission of a character
}

\author{
M.A. COMENDADOR *, Nadine PLUS $* *$, C. LOUIS $* *$ \\ and $M$. LOPEZ-FERBER ** \\ with the technical collaboration of Andree KUHL and G. KUHL \\ * Departamento de Genética, Facultad de Biologia \\ Universidad de Oviedo, 33006 Oviedo, Spain \\ **I.N.R.A.C.N.R.S., Station de Recherches de Pathologie comparée \\ F 30380 Saint-Christol
}

\begin{abstract}
Summary
The $D$. simulans SimES strain is characterized by the presence of individuals of $\mathrm{S}$ phenotype (malformation and/or suppression of thoracic bristles, mainly the dorsocentral and scutellar ones), with a variable frequency ranging approximately from 50 p. 100 to 60 p. 100 . Since this phenotype is transmitted maternally, the presence of a microorganism responsible for that phenotype can be suspected.

The presence of 2 pathogenic microorganisms in the SimES strain, a microsporidia (Nosema kingi) and a Picornavirus (Drosophila $\mathrm{C}$ virus) was detected. In flies free of both microorganisms, the $\mathrm{S}$ phenotype maintains the same properties, and therefore, it can be concluded that they play no part in the $S$ phenotype determination. However, several experimental results, i.e. effects of temperature, infectious action of SimES extracts, and no effect of antibiotics, have led us to formulate the hypothesis that $\mathbf{S}$ phenotype is duc to action of slightly pathogenic virus transovarially transmitted.
\end{abstract}

Key words : Endemic microorganisms, Drosophila simulans SimES, non-mendelian character, hereditary virus, pathology of morphogenesis.

\begin{abstract}
Résumé
Micro-organismes endémiques d'une souche de Drosophila simulans et leurs relations avec la transmission non-mendélienne d'un caractère
\end{abstract}

La souche SimES de Drosophila simulans se caractérise par la présence d'individus de phénotype $S$ [malformations et (ou) suppression de soies thoraciques, principalement des dorso-centrales et des scutellaires], avec une fréquence de 50 à $60 \mathrm{p}$. 100. Ce phénotype est transmis maternellement, rendant donc plausible a priori le rôle de micro-organismes dans son déterminisme.

De fait, 2 micro-organismes pathogènes ont été trouvés dans la souche SimES, la 
microsporidie Nosema kingi et un Picornavirus, le virus C de la Drosophile. Dans les mouches débarrassées de ces 2 micro-organismes, le phénotype $S$ se maintient avec les mêmes propriétés. Ces 2 agents ne jouent donc aucun rôle dans le déterminisme de ce phénomène. Cependant, certains résultats expérimentaux (effets de la température, pouvoir infectieux des extraits de drosophiles SimES, absence d'action d'antibiotiques) conduisent à formuler l'hypothèse que le phénotype $S$ est dû à l'action d'un virus légèrement pathogène, à transmission transovarienne.

Mots clés : Micro-organismes endémiques, Drosophila simulans SimES, caractère non mendélien, virus héréditaire, pathologie de la morphogénèse.

\section{Introduction}

The $\mathbf{S}$ character was found in the SimES population of Drosophila simulans collected in the Azores Islands. The $\mathrm{S}$ flies exhibit abnormalities of thoracic bristles, mostly the dorsocentral and scutellar ones. This character is hereditary, but does not follow mendelian laws (ComENDADOR, $1980 \mathrm{a}, \mathrm{b}$ ). Other notable features associated with the $S$ character are : (i) the number of $S$ phenotype bristles varies from fly to fly ; (ii) there is an evident sexual dimorphism, the $S$ phenotype being more frequently found in males than in females; (iii) the offspring of $S \times S$ crosses is composed of $S$ flies (around 50-60 p. 100) and wild-type ones. Among these last ones, about 7 p. 100 produced offspring, in $F_{2}$, which are $S$; (iv) a strong bilateral asymmetry is observed : in $\mathbf{S}$ individuals with 2 or more abnormal bristles, these are more often localized on the same side of the body and $(v)$ the $S$ phenotype is very responsive to selection : after only 3 generations of selection, the mean number of $S$ bristles increased from $0.50 \pm 0.05$ to $5.35 \pm 0.20$ in females and from $1.04 \pm 0.08$ to $6.50 \pm 0.19$ in males.

TABLE 1

Abbreviations and symbols

\begin{tabular}{l|l}
\hline \hline DCV & $\begin{array}{l}\text { Drosophila C virus } \\
\text { Shenotype of the SimES strain }\end{array}$ \\
SimES & $\begin{array}{l}\text { A D. simulans strain derived from a wild population caught in } \\
\text { Azores Islands }\end{array}$ \\
SiMES-st & SimES strain free of $N$. kingi and DCV \\
\hline \hline
\end{tabular}

Few examples of maternal transmission of characters are known for the genus Drosophila. In 3 cases the causal factor appeared to be a microorganism : $\mathrm{CO}_{2}$ sensitivity is due to the Rhabdovirus sigma (BRUN \& Plus, 1980) ; lethality of male zygotes is induced by spiroplasmas (Williamson \& Poulson, 1979); the sterility of the hybrid in the $D$. paulistorum species complex is caused by mycoplasma-like particles (Daniels et al., 1977). The fourth case, the female sterility occurring between 
crosses of different Drosophila melanogaster strains, seems to be due to interaction between cytoplasmic property and a mobile chromosomal element (BrEgLiano et al., 1980 ; KidWell, 1983 ; PiCARd, 1978).

Thus, is seems reasonable to postulate that the $\mathbf{S}$ character, maternally transmitted in $D$. simulans, could be due to the presence of an endemic microorganism. It is interesting to note that the $S$ character is a morphological trait and not a physiological abnormality like all the above examples.

In fact, it was found that the original SimES strain kept in laboratory conditions was very weak and had a low fertility. In this report, we present firstly the results of the search for the pathogenic microorganisms in the SimES strain, and secondly, the results of the measures of some fitness parameters of the SimES strain free of these pathogenic microorganisms. Finally, these «cured» SimES strain properties were studied and we formulated an hypothesis to explain the persistent traits of this strain : the presence, in specific tissues of these flies, of a hereditary virus with low pathogenicity.

\section{Material and methods}

Drosophila strains. The strain in which the $\mathrm{S}$ character appeared was denominated SimES ; it was already described (COMENDADOR, $1980 \mathrm{a}$ and b). A second $D$. simulans strain (Madagascar) and a D. melanogaster one (Champetières) were utilized. Madagascar and Champetières (Plus et al., 1975) were both free of microorganisms.

Culture conditions. David's axenic medium (DAvID, 1959) was used in experiments for detecting microorganisms, checking for contamination through feeding or contact and measurement of fitness parameters. In other experiments, a medium composed of bread yeast, sugar and agar was utilized. The experiments, unless stated otherwise, were performed at $25^{\circ} \mathrm{C}$.

Detection of microorganisms. Microorganisms, other than viruses, were searched for using phase contract microscopy of tissue and haemolymph, and smears of flies after fixation in methanol and staining with 5 p. 100 solution of Giemsa for 12 hours.

The presence of viruses was tested by injecting a filtered $(0.45 \mu \mathrm{m})$ extract of SimES flies into fifty Champetières flies, which died in 3 days; these were extracted in 10 times their volume of Ringer solution, clarified by centrifugation for 15 minutes at $2000 \mathrm{~g}$, negatively stained with $2 \mathrm{p}$. 100 phosphotungstic acid and examined by electron microscopy.

Serological tests. Gel double diffusion (OuTCHERLONY, 1958) was done on extracts of SimES flies to test for the presence of viruses related to Drosophila $\mathrm{C}$ virus using antiserum 50 against DCV (PLus et al., 1978).

\section{Measurements of fitness parameters.}

- Fecundity, viability and rate of development. Thirty pairs each of $\mathrm{S}$ and wild-type flies, offspring of $S$ females, were isolated in tubes of nutrient medium and transferred daily for a period of 3 days. For each tube, the number of emerging 
adults was counted; the time of development, from egg to imaginal stage, was recorded.

- Longevity. Individual virgin males and females, progeny of $\mathbf{S}$ mothers, were isolated in tubes containing medium. The phenotype and number of days that elapsed between emergence and natural death were recorded.

- Egg sterilization and its effects. The egg sterilization was carried out by removal of the chorion: SimES eggs were treated for 10 minutes in 2 p. $100 \mathrm{NaOCl}$ and rinsed several times with Ringer's solution.

Sterilized (1250) and non-treated (600) eggs were transferred to tubes with axenic medium in groups of fifty. The difference in the number of eggs is due to the known deleterious effect of $\mathrm{NaOCl}$ solution on hatchability. The time between egg deposition and adult emergence was scored and the phenotype of each imago determined.

Temperature effects. The offspring of 10 pairs of $\mathrm{S}$ phenotype was bred at $17{ }^{\circ} \mathrm{C}$ and those of ten other pairs at $24^{\circ} \mathrm{C}$. For each tube, twenty $\mathrm{F}_{1}$ individuals of each sex were examined and the frequency of both $S$ and wild-type calculated.

Infectivity of the extracts of SimES flies. A crude extract was prepared by crushing about 100 flies, wild-type or S, in $2 \mathrm{ml}$ of Ringer's solution. One $\mathrm{ml}$ of each extract was poured on the eggs laid by wild-type females coming from $S$ mothers. Another $\mathrm{ml}$ was added, the following day, into the same tube on the larvae in the first instar. The phenotype of the emerging adults was determined for each tube.

\section{Testing the effect of antibiotics :}

1. Tetracycline. 30 tubes were prepared with the following concentrations of oxy-tetracycline (Pfeizer, Spain) in the culture medium : $0 \mathrm{mg} / 1,60 \mathrm{mg} / 1,120 \mathrm{mg} / 1$, $240 \mathrm{mg} / \mathrm{l}$ and $480 \mathrm{mg} / \mathrm{l}$. A pair of $\mathrm{S}$ flies was introduced into 10 tubes at each tetracycline concentration and transferred daily, for three days, into similar tubes. The degree of expression of the phenotype of the $F_{1}$ offspring was determined.

2. Other antibiotics. Penicillin, Kanamycin and Streptomycin (Sigma) were incorporated, separately, in culture tubes at the final concentrations of $0 \mathrm{mg} / \mathrm{l}$, $60 \mathrm{mg} / \mathrm{l}, 120 \mathrm{mg} / \mathrm{l}, 240 \mathrm{mg} / \mathrm{l}$ and $480 \mathrm{mg} / \mathrm{l}$. A single pair of $\mathrm{S}$ flies was introduced in each tube and the phenotype of the $F_{1}$ analyzed globally $(S$ or +$)$. In this experiment, in order to minimize the variability, the mothers selected were sisters exhibiting a uniform degree of expressivity of the character (4 missing chaetae); the fathers were brothers with 8 missing chaetae produced by a different pair.

\section{Results}

\section{A. Endemic pathogenic microorganisms and lack of effect upon the $S$ character}

A microsporidia was easily detected by light microscopy in smears of SimES flies of both $\mathrm{S}$ and wild-type phenotypes. This microsporidia has been characterized by M. Maurand as Nosema kingi (Kramer, 1964), endemic in some D. willistoni 
strains and known to be transmitted transovarially in this species. This mode of transmission was also observed in SimES flies since adults derived from dechorionated eggs were still infected with $N$. kingi. A disharmony in the cycles of the parasite and the host was induced by lowering the breeding temperature from $25^{\circ} \mathrm{C}$ to $17^{\circ} \mathrm{C}$. After a few generations, the test for the presence of microsporidia was negative and remained negative during all our work.

A second pathogenic microorganism was discovered after injecting a filtered SimES extract into Champetières flies; the injected flies died within 3 days. This early death is the usual symptom of the presence of the pathogenic Drosophila C virus (DCV) and, indeed, Picorna-like virions were observed using the electron microscope, in an extract of dead flies. The virions were further characterized by immunodiffusion against anti-DCV serum (Jousser et al., 1972) and a precipitating line was obtained.

It is known that DCV is transmitted in D. melanogaster from one generation to another only through surface contamination and it is not present inside the egg (BRUN \& Plus, 1980 ; Jousset et al., 1972). To determine if the mode of transmission was the same in $D$. simulans, we dechorionated SimES eggs, free of $N$. kingi, using $\mathrm{NaOCl}$. Flies coming from these eggs were shown to be free of DCV since no death occurred when several groups of 50 Champetières flies were injected with extracts of these flies. This «healthy strain of $D$. simulans, free of $N$. kingi and DCV, obtained from the original SimES stock and called SimES-st, was shown to have 2 properties : (i) it was more viable than the original strain and (ii) it retained the $\mathbf{S}$ character. This last fact allows us to reject the hypothesis of a fundamental role of these 2 pathogenic microorganisms in the control and transmission of the $\mathrm{S}$ character.

\section{B. Parameters of fitness of the $S$ phenotype D. simulans free of pathogenic microorganisms (N. kingi and DCV), (SimES-st stock)}

Some parameters of fitness (fecundity, fertility and rate of development) were measured for both $S$ and wild-type flies from the same parents $(S \times S$ and $+\times+)$; as stated above, the wild-type individuals transmit the $S$ phenotype with a low frequency.

1. Fecundity. The mean number of eggs, laid over a period of 3 days by every pair of flies is shown in table $2 \mathrm{~A}$. The wild-type flies have a fecundity significantly higher than $S$ ones $(t=2.34, p<0.05)$, though the difference between the 2 means, 9.86 eggs, is not very important.

2. Viability. The egg-adult viability of flies from the same crosses is shown in table 2B. Viability is also significantly higher for the offspring of wild-type flies than for $S$ ones $\left(\chi^{2}=40.79, \mathrm{p}<0.001\right)$; here also, the difference, 9.40 p. 100 is small. Table 3 shows that fecundity and viability of $S \times S$ matings are negatively correlated with the number of abnormal dorsocentral and scutellar bristles of $S$ mothers. This fact is further support for the maternal inheritance of this character.

3. Rate of development. The rate of development of the offspring of the 2 types of crosses was measured during the same experiment (table 2C), but no significant difference was detected between the means. Nevertheless, offspring from wildtype parents had a lower variance, females $(F=2.23, p<0.001)$ as well as males $(\mathrm{F}=2.34, \mathrm{p}<0.001)$. 
TABLE 2

Fecundity, viability and time of development (in days) of wild-type and $S$ flies.

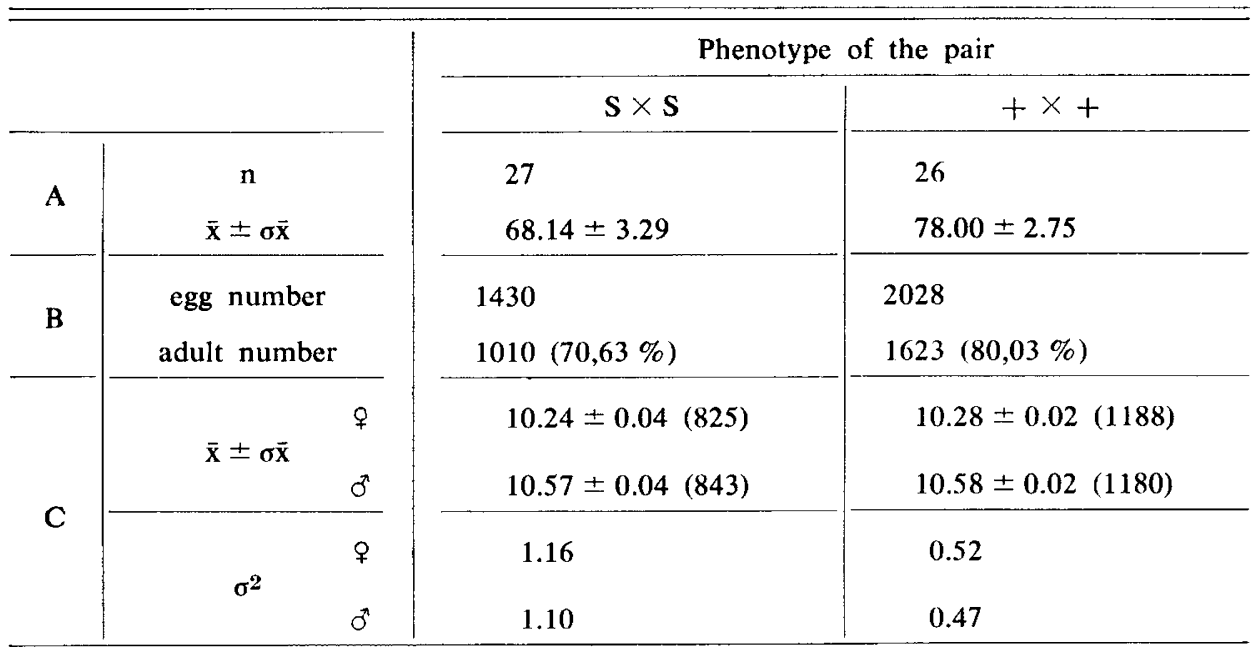

A : mean number of eggs laid during a period of 3 days by fertile pairs of $S$ and wild-type phenotypes ( $\mathrm{n}=$ number of pairs, $\overrightarrow{\mathrm{x}}=$ mean).

B : egg-adult viability of the offspring from the pairs of $2 \mathrm{~A}$ section (between brackets, survival percentage).

$\mathrm{C}$ : mean development time of offspring from $\mathrm{S} \times \mathrm{S}$ and $+\times+$ crosses and its variance (between brackets total number of individuals).

TABLE 3

Correlation between the phenotype (number of abnormal bristles)

and the fecundity and viability (after arcsin transformation) in the cross $S \times S$.

\begin{tabular}{|c|c|c|c|c|}
\hline \multicolumn{2}{|c|}{ Variables } & $\mathrm{r}$ & df & $\mathbf{p}$ \\
\hline \multicolumn{2}{|c|}{ Fecundity-maternal phenotype $(*)$} & -0.4342 & 27 & 0.05 \\
\hline \multicolumn{2}{|c|}{ Fecundity-paternal phenotype $(*)$} & -0.0227 & 27 & ns \\
\hline \multicolumn{2}{|c|}{ Viability-maternal phenotype $(* *)$} & -0.5968 & 21 & 0.01 \\
\hline \multicolumn{2}{|c|}{ Viability-paternal phenotype $(* *)$} & -0.2197 & 21 & ns \\
\hline \multicolumn{5}{|c|}{$\begin{array}{l}\mathbf{r}=\text { correlation coefficient. } \\
\mathbf{d f}=\text { degrees of freedom. }\end{array}$} \\
\hline \multicolumn{5}{|c|}{$\begin{array}{l}\left({ }^{*}\right) \\
(* *) \\
(* a s e d\end{array}$} \\
\hline
\end{tabular}

4. Effect of egg sterilization on the phenotype of the imagos and the duration of development. When batches of eggs from $\mathrm{S} \times \mathrm{S}$ pairs were sterilized with $\mathrm{NaOCl}$, the frequency of adults of normal phenotype increased in both sexes, significantly only among males $\left(\chi^{2}=7.19, p<0.001\right.$ ), (table 4B). The mean number of normal 


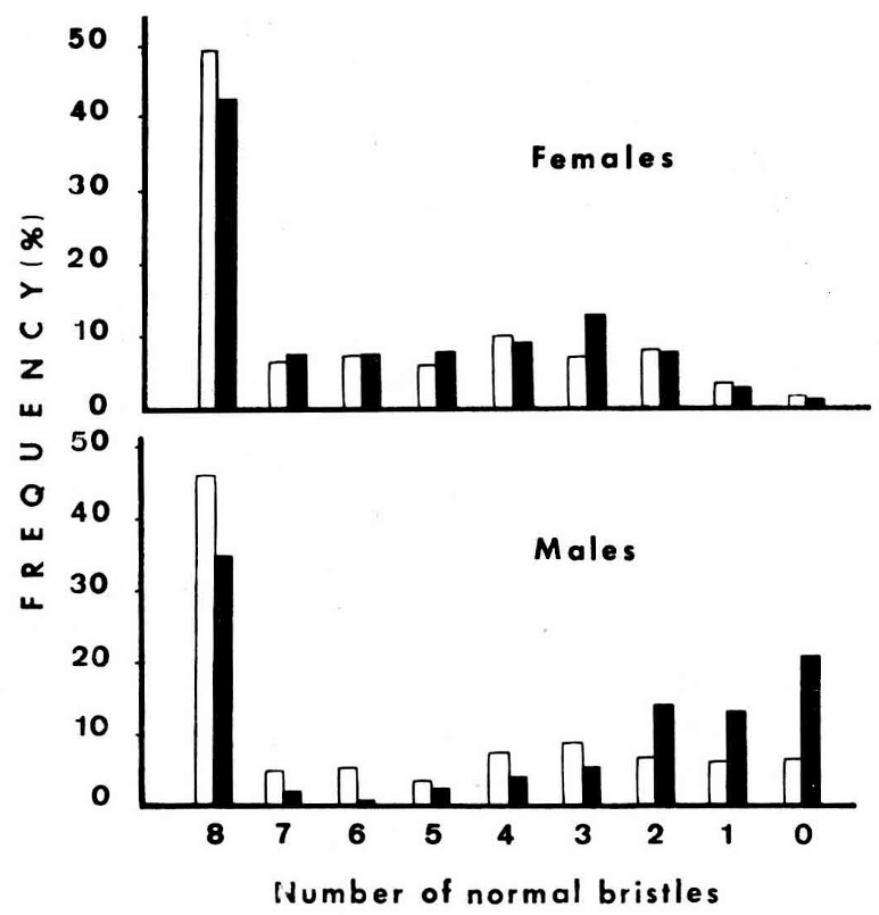

FIG. 1

Distribution of the number of normal bristles presented by females (upper) and males (lower) coming from sterilized (blank) and non-sterilized (filled) eggs in the cross $S \times S$.

bristles in these flies was higer than those from untreated eggs (table $4 \mathrm{~A}$ ). The difference is also significant only among males $(z=5.70, p<0.001)$. This effect according to sex is evident in the distribution pattern of the number of normal bristles (fig. 1). The distributions corresponding to females from sterilized and non-sterilized eggs are almost identical. The distribution corresponding to males from sterilized eggs is quite similar to that of the females, but the characteristic pattern of the control males is different for «low number of bristles». A higher percentage of this category is obtained.

The effects of egg sterilization on the duration of development were estimated using data from the same experiments. The results are shown in table $4 \mathrm{C}$. There are significant differences between wild-type and $S$ flies $\left(F=250.87, F_{1,1000,0.01}=6.64\right)$, independent of the sex or egg treatment (comparisons by the Scheffé test are all significant at $\alpha=0.01$ ).

These results confirm our previous finding that $\mathrm{S}$ flies take longer to develop. In the first experiment, the offspring of $S$ parents, which can be $S$ or wild-type, had a variance significantly higher than the offspring of wild-type parents. From the results of table $4 \mathrm{C}$, it is possible to infer that this higher variance is due to the phenotypic heterogeneity of the offspring of the $S \times S$ crosses. 
TABLE 4

Effect of egg sterilization upon the expressivity of $S$ character (between brackets, total numbers of individuals).

\begin{tabular}{|c|c|c|c|c|c|}
\hline & & \multicolumn{2}{|c|}{ Females } & \multicolumn{2}{|c|}{ Males } \\
\hline \multirow[t]{2}{*}{$\mathbf{A}$} & $\begin{array}{l}\text { Sterilized ... } \\
\text { Non-sterilized }\end{array}$ & \multicolumn{2}{|c|}{$\begin{array}{l}5.94 \pm 0.12(378) \\
5.71 \pm 0.16(221)\end{array}$} & \multicolumn{2}{|c|}{$\begin{array}{l}5.38 \pm 0.14(388) \\
3.93 \pm 0.22(228) \\
\end{array}$} \\
\hline & & + & $\mathrm{S}$ & + & $S$ \\
\hline B & $\begin{array}{l}\text { Sterilized } \ldots \\
\text { Non-sterilized }\end{array}$ & $\begin{array}{c}49.47 \pm 2.57 \\
(187) \\
42.99 \pm 3.33 \\
(95)\end{array}$ & $\begin{array}{c}50.53 \pm 2.57 \\
(191) \\
57.01 \pm 3.33 \\
(126)\end{array}$ & $\begin{array}{c}46.13 \pm 2.53 \\
(179) \\
35.09 \pm 3.16 \\
(80)\end{array}$ & $\begin{array}{c}53.87 \pm 2.53 \\
(209) \\
64.91 \pm 3.16 \\
(148)\end{array}$ \\
\hline $\mathrm{C}$ & $\begin{array}{l}\text { Sterilized ... } \\
\text { Non-sterilized }\end{array}$ & $\begin{array}{c}10.35 \pm 0.05 \\
(185) \\
10.23 \pm 0.05 \\
(95)\end{array}$ & $\begin{array}{c}11.03 \pm 0.06 \\
(201) \\
10.97 \pm 0.08 \\
(125)\end{array}$ & $\begin{array}{c}10.43 \pm 0.06 \\
(137) \\
10.30 \pm 0.05 \\
(80)\end{array}$ & $\begin{array}{c}11.19 \pm 0.07 \\
(204) \\
11.04 \pm 0.07 \\
(148)\end{array}$ \\
\hline
\end{tabular}

A : mean number of normal bristles in individuals derived from sterilized and non-sterilized eggs.

B : frequencies (in p. 100 of each phenotype $S$ and wild-type) of individuals derived from sterilized and non-sterilized eggs.

C : mean development time (in days) of $\mathrm{S}$ and wild-type flies coming from sterilized and non-sterilized eggs.

5. Longevity. Figure 2 shows the mean longevity of wild-type and $\mathrm{S}$ individuals from the same parents. The life span of wild-type flies is significantly higher than that of $S$ phenotype, for females $(z=3.9, p<0.001)$ as well as for males $(z=3.1$, $\mathrm{p}<0.001)$. In addition, a positive relation seems to exist between the number of normal bristles and the life span. Nevertheless, this correlation does not reach a significant level $\left(r_{2,375}=0.8537\right.$ for the females and $r_{3,443}=0.7269$ for the males), due to the small number of categories of the first variable and to the number of individuals recorded.

\section{Effect of the temperature on the expression of $S$ phenotype}

Table 5 presents the frequency of $S$ and normal progeny from the cross $S \times S$ raised at $24^{\circ} \mathrm{C}$ or $17^{\circ} \mathrm{C}$. Flies raised at $17^{\circ} \mathrm{C}$ show a significantly smaller percentage of $\mathrm{S}$ phenotype than those raised at $24{ }^{\circ} \mathrm{C}$ ( $\chi^{2}$ females : $53.57 \mathrm{p}<0.001 ; \chi^{2}$ males : $66.02 \mathrm{p}<0.001$ ). For males, the percentage of $\mathrm{S}$ flies is 2 times higher at $24{ }^{\circ} \mathrm{C}$. So, the expression of $\mathrm{S}$ character is conditioned by temperature during pre-imaginal development. 


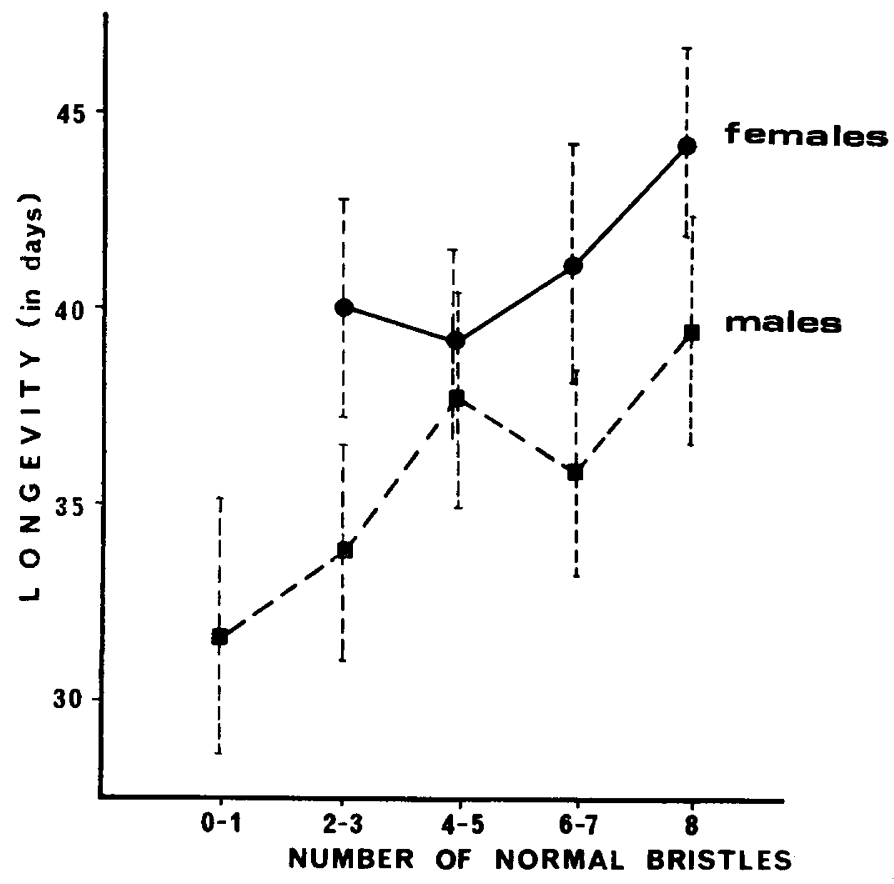

FIG. 2

Mean longevity $(\bar{x} \pm 1.96 \overline{\sigma x})$ of $S$ and wild-type flies coming from $S \times S$ crosses, according to the number of normal bristles. (- females, males).

TABLE 5

Percentage of wild-type and $S$ flies, $F_{1}$ from $S \times S$ crosses, according to the temperature of pre-imaginal development $\left(17^{\circ} \mathrm{C}\right.$ or $\left.24^{\circ} \mathrm{C}\right)$. Between brackets, total numbers of flies.

\begin{tabular}{|c|c|c|c|c|}
\hline \multirow{2}{*}{$\begin{array}{l}\text { Pheno- } \\
\text { type }\end{array}$} & \multicolumn{2}{|c|}{$17^{\circ} \mathrm{C}$} & \multicolumn{2}{|c|}{$24^{\circ} \mathrm{C}$} \\
\hline & Females & Males & Females & Males \\
\hline+ & $\begin{array}{c}85.50 \pm 2.49 \\
(171)\end{array}$ & $\begin{array}{c}83.50 \pm 2.62 \\
(167)\end{array}$ & $\begin{array}{c}51.50 \pm 3.53 \\
(103)\end{array}$ & $\begin{array}{c}44.50 \pm 3.51 \\
(89)\end{array}$ \\
\hline $\mathrm{S}$ & $\begin{array}{c}14.50 \pm 2.49 \\
\text { (29) }\end{array}$ & $\begin{array}{c}16.50 \pm 2.62 \\
(33)\end{array}$ & $\begin{array}{c}48.50 \pm 3.53 \\
(97)\end{array}$ & $\begin{array}{c}55.50 \pm 3.51 \\
(111)\end{array}$ \\
\hline
\end{tabular}


D. Lack of effect of antibiotics on the S character of the SimES stock

1. Oxy-tetracycline. Five samples of SimES-st flies (free of $N$. kingi and DCV), were grown from eggs to adults on nutrient medium containing increasing concentrations of oxy-tetracycline (table 6). No difference was observed in comparison to the controls $\left(F=0.037, F_{4,1000}, 0.05=2.38\right)$. Oxy-tetracycline is known to be effective against Bacteria, Rickettsias, Spirochetes, Bedsonies, Mycoplasmas and Protozoa. Is is not very likely, hence, that microorganisms sensitive to tetracycline are responsible for the $S$ phenotype. We did not found any association between sex and dose (concentration of anitibiotic) $\left(F=0.43, F_{4,1000,0.05}=2.38\right)$.

\section{TABLE 6}

Mean number of normal bristles on SimES-st males and females treated with different doses of oxy-tetracycline (between brackets, total number of individuals).

\begin{tabular}{|c|c|c|c|c|c|}
\hline \multicolumn{6}{|c|}{ Quantity of oxy-tetracycline (in $\mathrm{mg}$ ) by litre of medium } \\
\hline & 0 & 60 & 120 & 240 & 480 \\
\hline Females & $\begin{array}{c}5.37 \pm 0.21 \\
(112)\end{array}$ & $\begin{array}{c}5.35 \pm 0.22 \\
(99)\end{array}$ & $\begin{array}{c}5.21 \pm 0.23 \\
(123)\end{array}$ & $\begin{array}{c}5.27 \pm 0.20 \\
(107)\end{array}$ & $\begin{array}{l}5.19 \pm 0.20 \\
\quad(117)\end{array}$ \\
\hline Males & $\begin{array}{c}4.29 \pm 0.21 \\
(102)\end{array}$ & $\begin{array}{c}4.26 \pm 0.21 \\
(92)\end{array}$ & $\begin{array}{c}4.52 \pm 0.19 \\
(131)\end{array}$ & $\begin{array}{c}4.31 \pm 0.19 \\
(113)\end{array}$ & $\begin{array}{c}4.48 \pm 0.20 \\
(109)\end{array}$ \\
\hline
\end{tabular}

2. Other antibiotics. (Penicillin, Streptomycin, Kanamycin). No significant difference was found between the proportions of $S$ and wild-type flies, in the $F_{1}$ coming from the antibiotic containing tubes, compared to the control one $\left(\chi^{2}=3.63, \chi^{2}{ }_{8,0.05}=\right.$ 15.51).

\section{E. Contagious power of the $S$ character}

Samples of eggs from SimES-st parents of the normal phenotype were grown in ordinary medium or in medium supplemented with an extract of $\mathbf{S}$ or wild-type flies of the SimES-st stock. Table 7 shows that significantly greater numbers of $\mathrm{S}$ phenotype flies are obtained in the "treated» samples $\left(\chi^{2}=30.80, p<0.001\right)$. Also, the frequency of $\mathbf{S}$ flies observed is higher after addition of $S$ extract than after addition of wild type extract, though the difference is not significant $\left(\chi^{2}=1.30,0.20<p<0.30\right.$ ). These results are very similar to those obtained previously (COMENDADOR, $1980 \mathrm{~b}$ ). However, similar feeding experiments have been done using D. melanogaster larvae or D. simulans (Madagascar strain) larvae and have given negative results. Thus, it is likely that the $\mathrm{S}$ determinant is contagious, by contact or by feeding, but only in a permissive host strain. 
TABLE 7

Percentage of wild-type and $S$ imagos from SimES-st first instar larvae, progeny of $+X+$ crosses, treated or not with extracts from SimES-st ${ }_{i}+$ or SimES-st $S$ flies (between brackets, the number of flies).

\begin{tabular}{|c|c|c|c|c|}
\hline \multirow{2}{*}{$\begin{array}{l}\text { Origin } \\
\text { of the extract added }\end{array}$} & \multicolumn{2}{|c|}{ Experiment 1} & \multicolumn{2}{|c|}{ Experiment 2} \\
\hline & + & S & + & $\mathbf{S}$ \\
\hline SimES wild-type $\ldots \ldots \ldots$ & $\begin{array}{l}86.34 \\
(354)\end{array}$ & $\begin{array}{c}13.65 \\
(56)\end{array}$ & & \\
\hline SimES $S$ phenotype $\ldots \ldots \ldots$ & $\begin{array}{l}83.05 \\
(201)\end{array}$ & $\begin{array}{c}16.94 \\
(41)\end{array}$ & $\begin{array}{l}70.42 \\
(169)\end{array}$ & $\begin{array}{c}29.58 \\
(71)\end{array}$ \\
\hline Nothing . & $\begin{array}{l}92.47 \\
(381)\end{array}$ & $\begin{array}{l}7.52 \\
(31)\end{array}$ & $\begin{array}{r}77.32 \\
(75) \\
\end{array}$ & $\begin{array}{c}22.68 \\
(22) \\
\end{array}$ \\
\hline Nothing . . & $\begin{array}{l}91.19 \\
(715)\end{array}$ & $\begin{array}{l}8.80 \\
(69)\end{array}$ & & \\
\hline
\end{tabular}

\section{Discussion}

It has been demonstrated that the $\mathrm{S}$ character in the $D$. simulans SimES strain was hereditary, but not according to Mendelian laws (Comendador, $1980 \mathrm{a}, \mathrm{b}$ ).

As the majority of the abnormalities maternally transmitted in Drosophila species were due to the presence of microorganisms, it seemed logical to investigate their presence in the SimES strain.

Two microorganisms ( $N$. kingi and Drosophila $\mathrm{C}$ virus) were readily detected in the SimES strain; however, their elimination did not change the main characteristics related to the $S$ phenotype. The recovery of nearly normal vigor of the SimES-st strain is not surprising as both of them are known to be very pathogenic (JousseT et al., 1972 ; KRAMER, 1964). The fact that some of the flies obtained from disinfected eggs still exhibit the $S$ phenotype clearly indicates a transovogonial transmission of the causal factor. But, egg sterilization had 2 consequences in that frequency of normal flies and mean number of normal bristles were both higher than in unsterilized eggs. These differences could be due to contamination by the causal agent through the chorion, by contact or by ingestion; it could also reflect a different rate of survival of the $\mathrm{S}$ or wild-type eggs.

The SimES-st cured stock had a fitness within the normal limits of $D$. simulans species. Nevertheless, wild-type individuals were constantly and significantly better than the $\mathbf{S}$ flies with regard to several parameters. The flies compared were the offspring of $S \times S$ crosses, so, these differences could not be due to genetic heterogeneity and, therefore, are not chromosomic ones. A significant correlation was indeed found between the phenotype of the females and different parameters of fitness. So, it seems that the responsible factor for the $\mathrm{S}$ phenotype slightly, but significantly, 
reduces fitness. In fact, the differences observed are underestimated as 7 p. 100 of the flies with normal appearance give $S$ offspring. In other words, the unknown factor is pathogenic. Such small differences of fitness have been already observed between virus-free and infected $D$. melanogaster of the same genotype : the Picornavirus $\mathrm{P}$ affects the longevity of both sexes and the fertility of females (DAvID \& PLUS, 1971) ; 2 strains of Rhabdovirus sigma have been shown to have a deleterious effect ; one reduced the rate of egg hatching from 0.89 to 0.69 (SEECOF, 1964), another reduced the fertility of infected females by a factor of 1.6 (BRUN \& PLUS, 1980; JupIN et al., 1968). The 2 viruses are endemic, heritable and sensitive to temperature. It is interesting to recall that the factor responsible for the $S$ phenotype is very likely sensitive to temperature since flies grown at $17{ }^{\circ} \mathrm{C}$ showed a lower frequency of $\mathrm{S}$ phenotype than those grown at $24^{\circ} \mathrm{C}$. The possible role of a microorganism in the control of the $S$ character is enhanced by our finding of a slight «infectivity » of an extract of SimES-st flies on first instar larvae of the same stock. The absence of action of antibiotics on the expression of the $S$ phenotype led us to postulate that the causative microorganism could be a virus.

After injecting mice with some Retrovirus, Rowe (1983) observed symptoms which remind one of the $S$ phenotype : the whiskers of the infected animals were asymmetrical, sparse, short, curved and even in some cases the vibrissae were lost. This author suggests that there arose, in the infected mice, recombinant viruses showing new tissular specificity.

According to our results, the hypothetical virus that we postulate as being responsible for the $\mathrm{S}$ phenotype, should possess 3 properties a priori. It should be : (i) maternally inherited; (ii) slightly pathogenic and (iii) mildly infectious but only to larvae of the SimES genotype (or other "permissive » genotypes) thus depending of host genes. Experiments are being carried out using standard virological techniques, to detect the presence of this hypothetical virus.

Received June 28, 1985.

Accepted December 23, 1985.

\section{Acknowledgements}

The authors thank P. Scotri for helpful comments on the manuscript, and J. Maurand for the classification of the microsporidia Nosema kingi. This work was supported in part by the Spanish-French Integrated Action 81/16/81.

\section{References}

Bregliano J.C., Picard G., Bucheton A., Pelisson A., Lavige J.M., L'Héritier P., 1980. Hybrid dysgenesis in Drosophila melanogaster. Science, 207, 606-611.

Brun G., Plus N., 1980. The viruses of Drosophila. In : Ashrurner M., Wright T.R.F. (ed.), The genetics and biology of Drosophila, 2d, 625-702, Academic Press, London.

Comendador M.A., 1980 a. Abnormal bristles that show maternal inheritance in Drosophila simulans. Drosophila Inf. Serv., 55, 26-28. 
COMEndador M.A., 1980 b. Herencia materna de alteraciones estructurales de las quetas de Drosophila simulans. Rev. Fac. Cien. Univ. Oviedo, 20-21, 3-13.

Daniels S.B., Ehrman L., Perelle I.B., 1977. Hybrid inviability; a third reproductive isolating mechanism in the Drosophila paulistorum species complex. Biol. Zbl., 96, 385-406.

Davıd J., 1959. Etude quantitative du développement de la drosophile élevée en milieu axénique. I. Mise au point d'un milieu non fermenté. Bull. Biol. Fr. Belg., 93, 472-489.

David J., Plus N., 1971. Le virus $P$ de la drosophile : comparaison de la longévité et de la fécondité des mouches infectées par injection ou par contamination naturelle. Ann. Inst. Pasteur, 120, 107-119.

Jousset F.X., Plus N., Croizier G., Thomas M., 1972. Existence chez Drosophila de deux groupes de Picornavirus de propriétés sérologiques différentes. C.R. Acad. Sciences Sér. D., 275, 3043-3046.

Jousset F.X., Plus N., 1972. - Etude de la transmission horizontale et de la transmission verticale des Picornavirus de Drosophila melanogaster et de D. immigrans. Ann. Microbiol. (Inst. Pasteur), 126 B, 231-249.

Jupin N., Plus N., Fleuriet A., 1968. Action d'une souche de virus sigma sur la fertilité des Drosophiles femelles. Ann. Institut Pasteur, 114, 567-574.

Kidwell M., 1983. Evolution of hybrid dysgenesis determinants in Drosop/hila melanogaster. Proc. natl. Acad. Sci. U.S.A., 80, 1655-1659.

Kramer J.P., 1964. Nosema kingi spn., a microsporidian from Drosophila willistoni Sturtevant, and its infectivity for other muscoids. J. Insect Pathol., 6, 491-499.

Outcherlony O., 1958. Diffusion in gel, method for immunological analysis. Prog. allergy, $5,1-78$.

PICARD G., 1978. Non-mendelian female sterility in Drosophila melanogaster. Further data on chromosomal contamination. Mol. Gen. Genet., 164, 235-247.

Plus N., Croizjer G., Jousset F.X., David J., 1975. Picornavirus of laboratory and wild Drosophila melanogaster : geographical distribution and serotypic composition. Ann. Microbiol. (Inst. Pasteur), 126 A, 107-117.

Plus N., Croizier G., Reinganum C., Scotti P., 1978. Cricket paralysis virus and Drosophila $\mathrm{C}$ virus : serological analysis and comparison of capsid polypeptides and host ranges. J. Inv. Path., 31, 296-302.

RowE W.P., 1983. Deformed whiskers in mice infected with certain exogenous leukemia virus. Science, 221, 562-564.

SeEcoF W.P., 1964. Deleterious effect on Drosophila development associated with the sigma virus infection. Virology, 22, 142-148.

Williamson D.L., Poulson D.F., 1979. Sex-ratio organisms (Spiroplasmas) of Drosophila. In : Whitcomb R.F., Tully J.G. (ed.), The Mycoplasma, 3, 175-208, Academic Press, New York. 